\title{
EFFICACY OF ANESTHETIC COCKTAIL WOUND INSTILLATION FOR POSTOPERATIVE ANALGESIA FOLLOWING POSTERIOR SPINAL SURGERY
}

\author{
Chayapon Trekajonsak*, Teerawat Poojinya**, Chaisiri Chaichankul*, \\ Roongrath Chitragran*, Sakpan Panyaporn*, Patchara Linsuwan**, Sompob Poopitaya*
}

\author{
*Department of Orthopedics, Phramongkutklao Hospital and Phramongkutklao College of \\ Medicine, Bangkok, Thailand \\ ** Department of Anesthesia, Phramongkutklao Hospital and Phramongkutklao College of \\ Medicine, Bangkok, Thailand
}

\begin{abstract}
Background: Posterior spinal surgery is a common procedure in orthopedic practices that causes severe pain after surgery. Proper postoperative pain controls not only benefit early mobilization and initiation of physiotherapy but they also play important roles in reducing morbidity and mortality.

Objective: This prospective, double-blinded, randomized controlled study investigated the efficacy of anesthetic cocktail wound instillation for postoperative analgesia following posterior spinal surgery.

Methods: After posterior spinal surgery, 54 patients were randomized to instill $20 \mathrm{~mL}$ of normal saline (Group N) or anesthetic cocktail consisting bupivacaine, ketorolac and morphine (Group A) in the wound after securing hemostasis and leaving a contact time of 60 seconds. After a dwell time of 60 seconds, the wound layers were closed without mopping or suctioning. All patients in both groups received patient-controlled analgesia using morphine for 24 hours post surgery, followed by standard analgesia. The analgesia consumption (morphine), visual analog scale (VAS) at specific hours after the operation, and time for first demand of analgesia were recorded. Morphine-related side effects were also monitored.

Results: The patients in group A consumed significantly less morphine at 4, 8, 12 and 16 hours after the surgery ( $p=0.048,0.007,0.005$ and 0.026 , respectively). In addition, they had lower VAS over the first 24 hours $(p<0.05)$ and longer median duration of first demand of analgesia $(p=0.013)$. Morphinerelated side effects were also lower in group A $(p=0.024)$.

Conclusion: The simple technique of wound instillation with anesthetic cocktail significantly reduced postoperative requirements of morphine and improved pain control with lower rates of nausea and vomiting over the first postoperative day after posterior spinal surgery.
\end{abstract}

Keywords: Posterior spinal surgery, Anesthetic cocktail, Postoperative pain, Wound instillation

J Southeast Asian Med Res 2020; 4(2): 75-83

http://www.jseamed.org

Correspondence to:

Trekajonsak C, Department of Orthopedics, Phramongkutklao Hospital and Phramongkutklao College of Medicine, Bangkok, Thailand

E-mail: Lang.drg@hotmail.com

Received: 19 June 2020

Revised: 26 November 2020

Accepted: 01 December 2020 


\section{Introduction}

Posteriorspinal surgery is acommon procedure in orthopedic and neurosurgical practices and considered one of the top six procedures causing the highest degree of postoperative pain especially for the initial few days. ${ }^{(1-3)}$ Pain is the fifth vital sign, ${ }^{(4)}$ that not only proper postoperative pain controls can benefit early mobilization and initiation of physiotherapy, but also plays important roles in reducing morbidity and mortality. Interest in understanding of the pathophysiology of acute pain and development in newer modalities of analgesic treatment have been increasing. Currently, several analgesic techniques are available. Intrathecal administration of opioids or local anesthetics and epidural administration of drugs using a catheter for continuous infusion provide the highest level of pain control; however, such therapies may be limited by highly invasive procedures, high cost, technical challenges, adverse or toxic effects of drugs and procedure-related complications such as reversible loss of sensory function and motor weakness. ${ }^{(2,5,6)}$ Although intravenous opioids or NSAIDs administration via Patient-Controlled Analgesia (PCA) provides less technical demand and decreased incidence of drug effects, analgesic efficacy remains inconclusive when compared with other options. ${ }^{(9-11)}$

Regional techniques, such as intra-articular injection and wound infiltration are commonly used alone or with other analgesic regimens for postoperative pain control. These offer many advantages, i.e., pain is relieved close to the damaged tissue, analgesia is provided when local anesthetic cocktails are used and opioidrelated side effects are substantially reduced by minimizing opioid consumption. ${ }^{(5,6,7)}$ Instilling local anesthetic drugs in the wound was found to provide postoperative analgesia in certain surgical and gynecological procedures. ${ }^{(1)}$ However, the role of a single time wound instillation with anesthetic cocktails in postoperative spinal surgery has not been explored earlier.
This prospective, double-blinded, randomized controlled study aimed to investigate the efficacy of anesthetic cocktail wound instillation for postoperative analgesia following posterior spinal surgery and evaluate opioid-related side effects.

\section{Methods}

This study was approved by the Institutional Review Board, Medical Department, Royal Thai Army. Written informed consent was obtained from all enrolled patients. Sample size calculation was used to determine the number of enrolled patients $(\mathrm{N}=27)$. This study enrolled 54 patients, 27 patients in each group, using the American Society of Anesthesiologists (ASA) physical status I, II and III undergoing posterior spinal surgery at Phramongkutklao Hospital from May 2017 to July 2018.

The inclusion criteria were patient's conditions, age, willingness and mentality. This study covered patients scheduled for posterior decompression with instrumentation not more than five levels with diagnosis of degenerative change of spine and failed conservative treatment, spinal fracture indicating surgery or patients who had complications due to undergoing prior spinal surgery. The patients' ages ranges from 18 to 80 years. Moreover, patients agreed to participate, had good mentality and were able to receive PCA in the postoperative period.

Patients who had ASA IV status, and were allergic to bupivacaine, ketorolac (NSAIDs) or morphine were excluded from the study. In addition, patients with massive bleeding (more than 2,000 mL), or cerebrospinal fluid leak were excluded after initial recruitment.

The block size of four was used to randomly separate patients in two groups. Group N represented the control group while Group A represented the intervention group that received anesthetic cocktails (Figure 1). We observed no difference in demographic data except age. Two patients in the intervention group were younger than other patients and underwent posterior spinal surgery due to fracture from trauma (Table 1). 


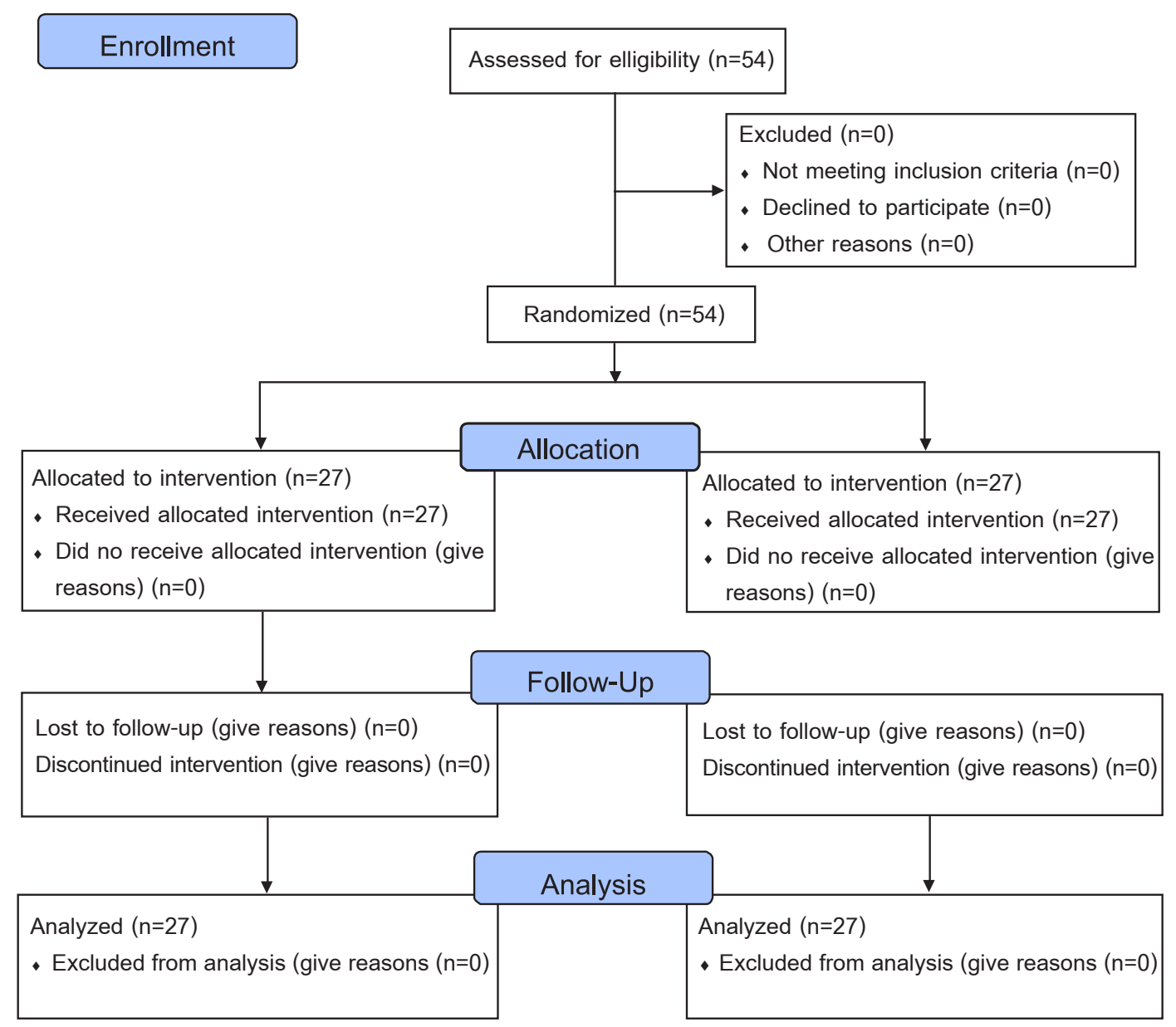

Flow Diagram

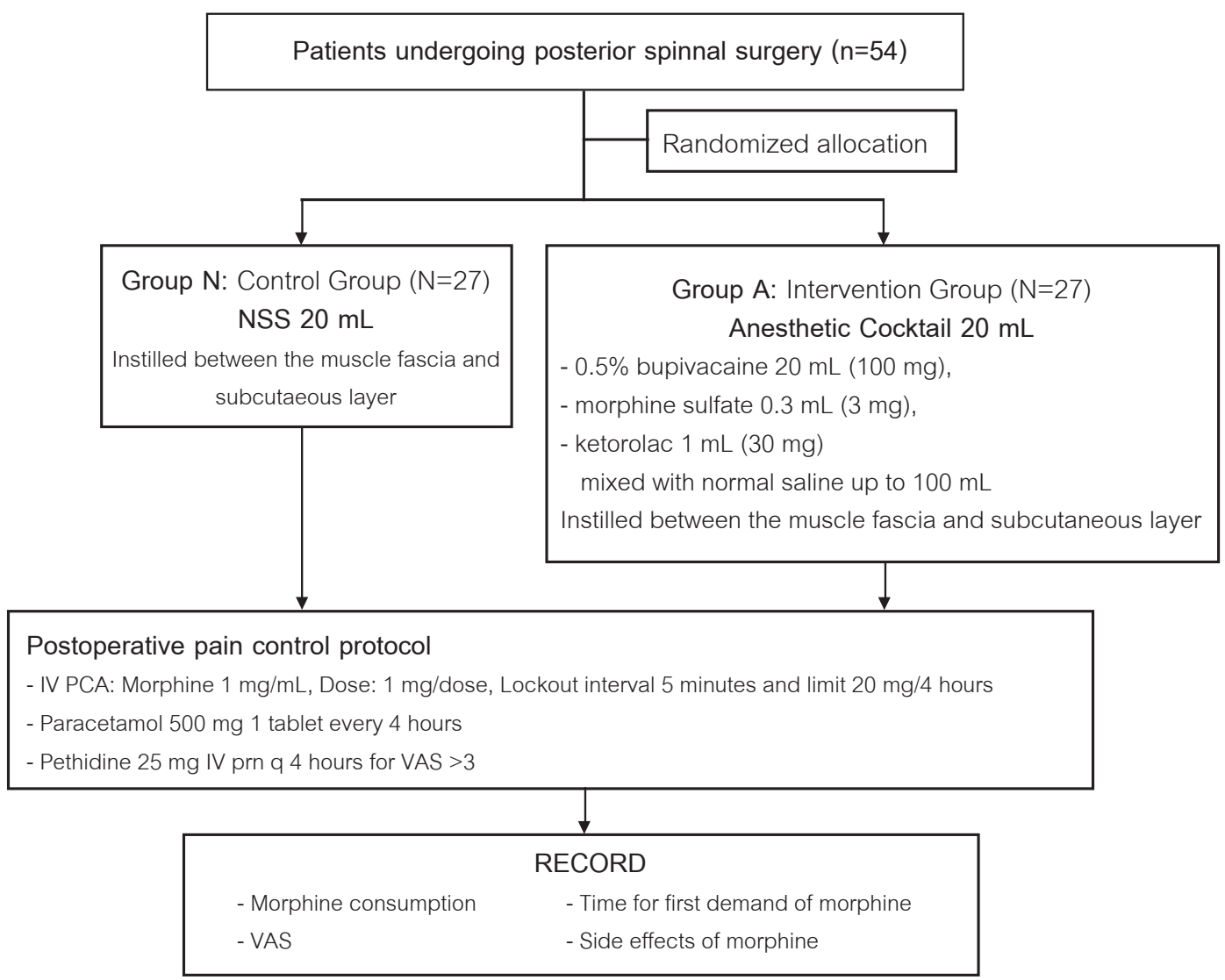

Figure 1. Flow chart shows the protocol of this study

IV PCA = Intravenous patient-controlled analgesia 

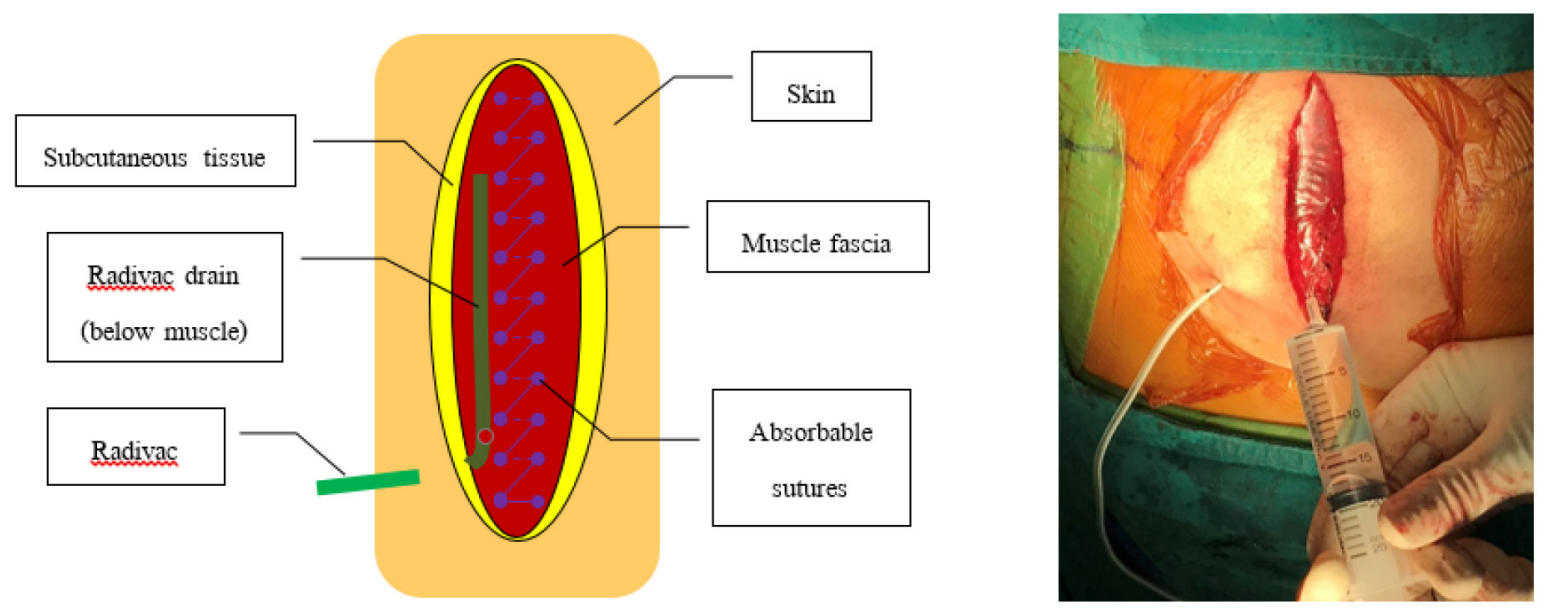

Figure 2. Instilled anesthetic cocktails or NSS $20 \mathrm{~mL}$ between the muscle fascia and subcutaneous layer

\section{Operative procedure}

All patients received standard general anesthesia with an appropriate sized endotracheal tube. Fentanyl 1-2 $\mu \mathrm{g} / \mathrm{kg}$ was administered intravenously after induced anesthesia for intraoperative analgesia. Once the surgical procedure was completed, hemostasis was secured and a radivac drain (without suction) was placed under the muscle layer. Patients in group $\mathrm{N}$ received $20 \mathrm{~mL}$ of normal saline instillation remaining in the wound between the muscle and subcutaneous layers for a dwell time of 60 seconds. Patients in group A received $20 \mathrm{~mL}$ of anesthetic cocktails for the same contact period (Figure 2). The anesthetic cocktails comprised $100 \mathrm{mg}$ bupivacaine $(0.5 \%, 20 \mathrm{~mL}), 3 \mathrm{mg}$ morphine sulfate $(0.3 \mathrm{~mL})$, and $30 \mathrm{mg}$ ketorolac $(1 \mathrm{~mL})$. These were mixed with sterile normal saline solution to make up a combined volume of $20 \mathrm{~mL}$. Then the wound was closed in layers without mopping or suctioning and radivac drain was opened after the patient was placed in the supine position.

Before surgery, all patients were informed about how to use the PCA device to control pain adjusted to their comfort level. Post-operation, both groups of patients received intravenous PCA for 24 hours using morphine. The PCA device was set to inject $1 \mathrm{mg}$ in $1 \mathrm{~mL}$ (100 mg of morphine in $90 \mathrm{~mL}$ normal saline) when patients pressed a button with a five-minute lockout period. No continuous infusion was available and the maximal dose was limited to $20 \mathrm{mg}$ every 4 hours. In addition to PCA, paracetamol 500 mg was administered every 4 hours. Moreover, pethidine $25 \mathrm{mg}$ was intravenously administered for rescue analgesia every four hours when the patient requested or visual analog scale (VAS) $>3$ after using maximal dose of PCA. The time for first demand of analgesia and total 24 hours analgesia consumption (morphine) were recorded. Morphine-related side effects were also monitored. In case of vomiting, metoclopramide $10 \mathrm{mg}$ was intravenously given at every eight hours until nausea and vomiting improved. Chlorpheniramine $10 \mathrm{mg}$ maleate was also used intravenously every six hours for pruritus. Omeprazole $40 \mathrm{mg}$ was given intravenously twice daily in all patients since the day of surgery to prevent gastrointestinal bleeding from stress ulcer.

Patients were assessed for postoperative pain by VAS, a 10-point scale ranging from " 0 " minimum or no pain to " 10 " maximum pain score perceived by the patient. Postoperative pain was assessed by an independent observer blinded to the study first at 0 hour (at recovery room, after extubation) and then at 2, 4, 8, 12, 18 and 24 hours after the surgery.

\section{Statistical Analysis}

Data were analyzed using IBM SPSS Software, Version 24. The Mann-Whitney U test was used to determine differences in estimating blood loss, amount of morphine consumption through PCA, time for first demand of analgesia and VAS between Groups N (normal saline) and A (anesthetic cocktails). Wilcoxon Signed 
Ranks test was also used to assess the amount of morphine consumed through PCA and VAS in both groups. Fisher's exact test was used to compare the ASA physical status, diagnostic group, number of demand pethidine for rescue analgesia and morphine-related side effects. Operative time was also analyzed for differences by independent t-test and number of spinal surgery levels was compared using the Chi-square test. A two-sided $p<0.05$ was considered statistically significant.

\section{Results}

Demographic data were compared between the two groups. No significant differences of operative conditions were observed including diagnosis, number of spinal surgery levels, operative time and estimated blood loss between the control and anesthetic cocktail groups (Table 1). We observed no intra-operative complications among any patients in either group. For the first 24 hours after surgery, the patient in the anesthetic cocktail group consumed significantly less morphine at 4, 8, 12 and 18 hours after the surgery $(p=0.048,0.007,0.005$, and 0.026 , respectively) but no difference was found for consumption at 2 and 24 hours ( $p=0.032$ and 0.166, respectively) (Figure 3). In addition, postoperative VAS was significantly lower in the anesthetic cocktail group at all time intervals of the first 24 hours compared with those of the control group (Figure 4) and longer median duration of first demand of analgesia $(p=0.013)$. The patients in the control group had eight times higher incidence $(p=0.024)$ of morphine-related side effects such as nausea, vomiting and pruritus compared with patients in the anesthetic cocktail group (29.63 versus $3.7 \%)$. No incidence of urinary retention or respiratory depression was reported in either group (Table 2).

\section{Discussion}

The result of this prospective, double-blinded, randomized controlled study showed that the group of patients having postoperative posterior spinal surgery receiving wound instillation with $20 \mathrm{~mL}$ of anesthetic cocktails (Group A) experienced better postoperative analgesia as compared with the group of patients receiving normal saline solution (Group N). Postoperative morphine consumption via PCA during the 4- to 18-hour interval, which was recorded at specific hours, showed that those in the normal saline group consumed substantially more analgesics than those in the anesthetic cocktail group. The postoperative pain scores (VAS) of the patients in anesthetic cocktail group were lower at all time points in first 24 hours. Furthermore, the time to first demand of analgesia was significantly prolonged in the anesthetic cocktail group.

Proper postoperative pain control after spinal surgery plays important roles in reducing morbidity and mortality. Currently several analgesic techniques are available. Wound infiltration with local anesthetics with or without adjuvant drugs has long been known to produce efficient postoperative analgesia. Bianconi et al. evaluated the efficacy of ropivacaine continuous wound instillation after joint replacement surgery and spine fusion surgery and found that significant analgesia, less pain scores and rescue medication requirements were observed compared with those of the placebo group. $(13,16)$ Pediatric patients following orthopedic extremity surgery received wound instillation of $0.5 \%$ bupivacaine $0.2 \mathrm{~mL} / \mathrm{kg}$ via a catheter. ${ }^{(14)}$ Yuenyongviwat et al. studied the effectiveness of local peri-articular injection with bupivacaine in total knee replacement surgery and found effective and prolonged postoperative analgesia with few morphine-related complications. ${ }^{(15)}$ In addition, Jonnavithula's study also reported that bupivacaine wound instillation technique was simple, safe and effective in managing acute pain after lumbar laminectomy. (1) Moreover, no complications were observed related to the infiltration of the local anesthetics. The efficacy and safety of local anesthetic drugs could reduce postoperative pain; however, using high volumes of local anesthetics should be restrained because they can affect the central nervous and cardiovascular systems. ${ }^{(27,28)}$ Anesthetic cocktails were used to reduce the dose of local anesthetics and could inhibit pain pathway by several mechanisms. Several studies have reported the efficacy and safety of peri- and 


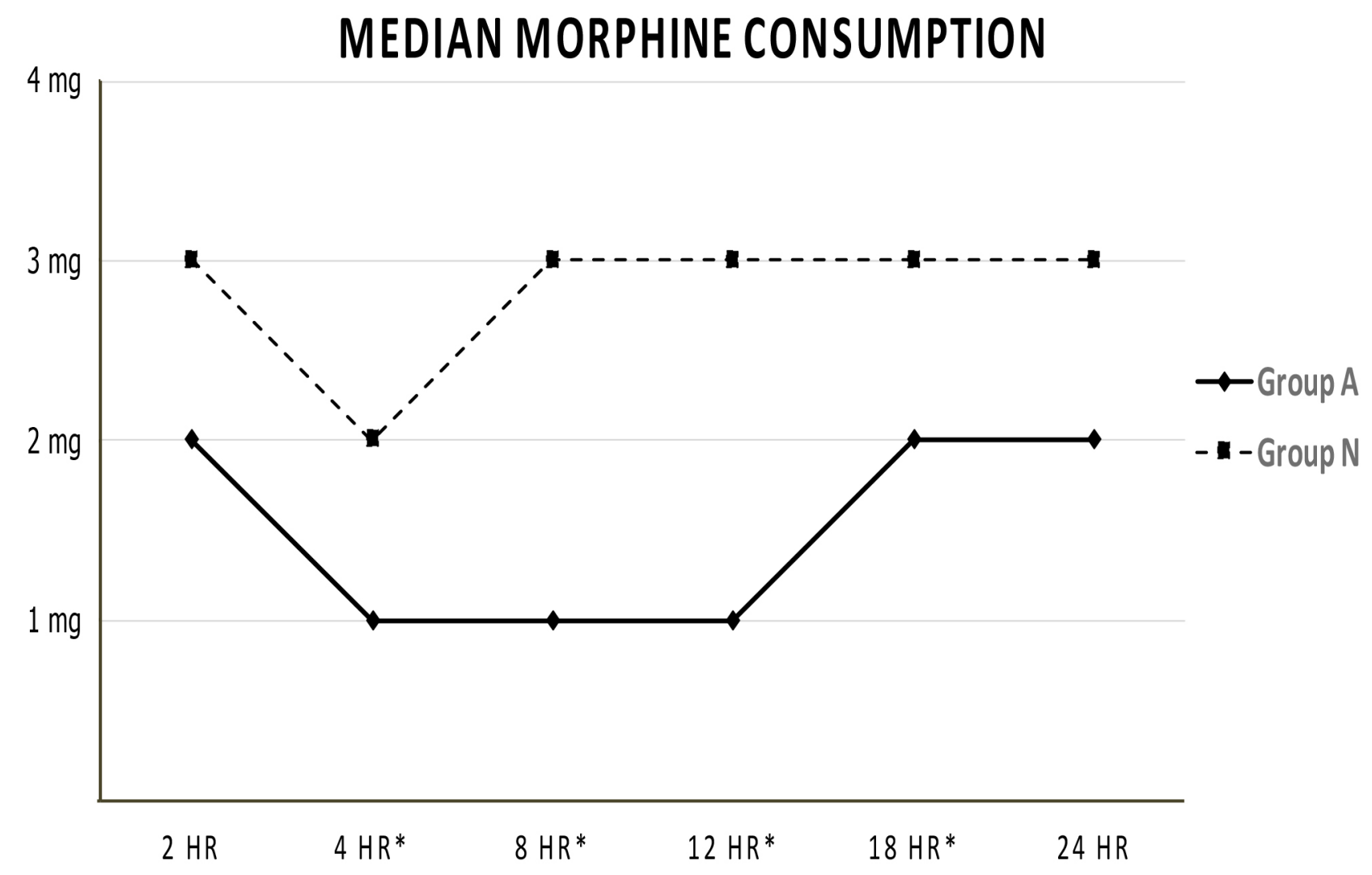

Figure 3. Comparison of median morphine consumption between group A (anesthetic cocktail group) and group $\mathrm{N}$ (control group) at specific postoperative time points (*p-value $<0.05$ using the Mann-Whitney U test)

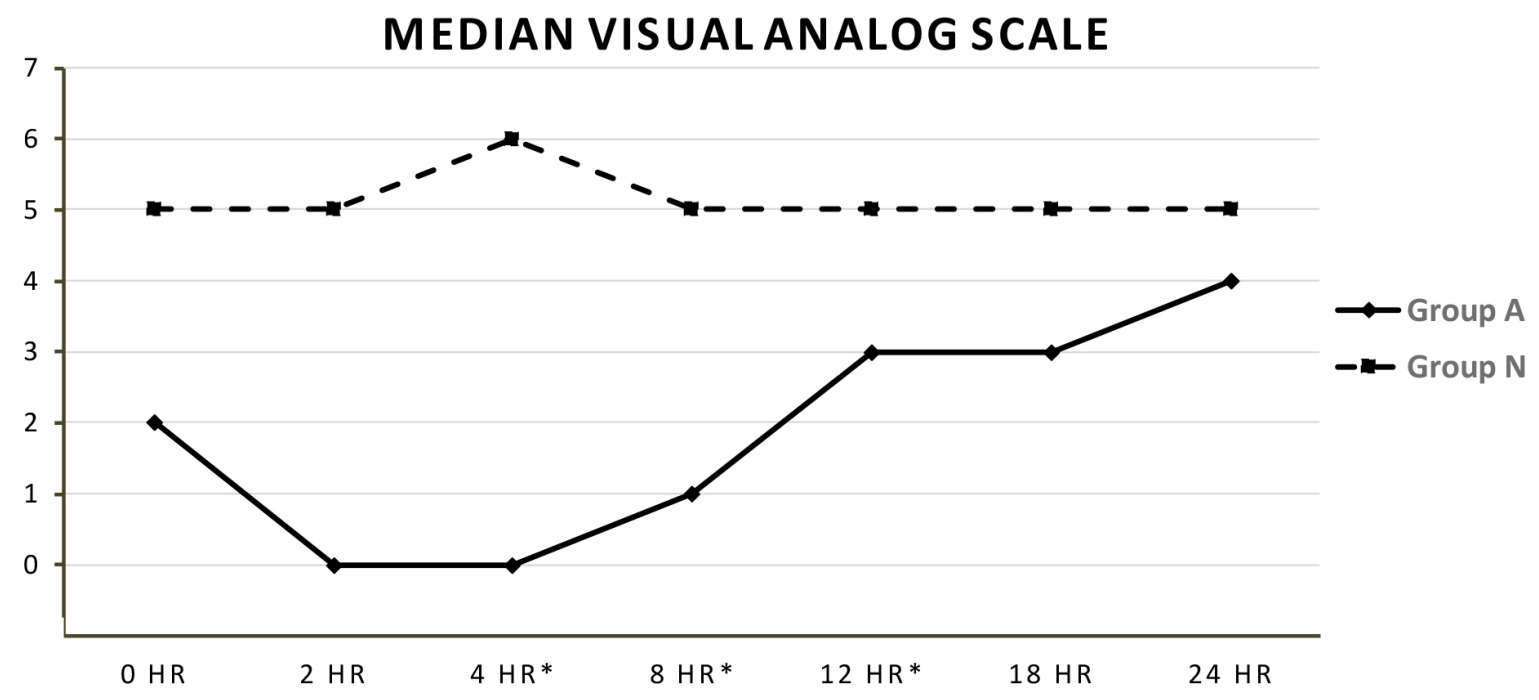

Figure 4. Comparison of median morphine consumption between group A (anesthetic cocktail group) and group $\mathrm{N}$ (control group) at specific postoperative time points (*p-value $<0.05$ using the Mann-Whitney U test) 
Table 1. Demographic data of enrolled participants and operative conditions ${ }^{\#}$

\begin{tabular}{lccc}
\hline \multicolumn{1}{c}{ Data } & $\begin{array}{c}\text { Group } \mathbf{N} \\
\mathbf{( N = 2 7 )}\end{array}$ & $\begin{array}{c}\text { Group A } \\
\mathbf{( N = 2 7 )}\end{array}$ & p-value \\
\hline \hline Demographic data & $18 / 9$ & $17 / 10$ & 0.776 \\
Gender (Female/Male) & $58.22 \pm 16.42$ & $66.33 \pm 9.51$ & $0.031^{*}$ \\
Age (years) & $159.04 \pm 10.45$ & $160.30 \pm 8.80$ & 0.634 \\
Height (cm) & $62.26 \pm 12.33$ & $64.30 \pm 12.04$ & 0.542 \\
Weight (kg) & $24.59 \pm 4.13$ & $24.96 \pm 3.62$ & 0.730 \\
BMI (kg/m $\left.{ }^{2}\right)$ & $6 / 18 / 3$ & $11 / 13 / 3$ & 0.380 \\
ASA status (I/II/III) & & & \\
Operative conditions & $17 / 3 / 7$ & $20 / 2 / 5$ & 0.688 \\
Diagnosis (D/F/FB) & $8 / 7 / 7 / 3 / 2$ & $4 / 6 / 9 / 7 / 1$ & 0.464 \\
Number of surgery levels (1/2/3/4/5) & $312.04 \pm 96.43$ & $335.37 \pm 82.3$ & 0.343 \\
Operative time (min) & $400(50-1500)$ & $500(10-1900)$ & 0.430 \\
Estimate blood loss (mL) & No & No & - \\
Intra-operative complication & \multicolumn{3}{c}{} \\
\hline
\end{tabular}

\# Data presented as mean $\pm \mathrm{SD}$, except for gender, ASA physical status, diagnosis, and number of surgery levels, which are presented as numbers. While estimate blood loss presented with median with min-max in parentheses and intra-operative complication presented as incidence.

(Group $\mathrm{N}=$ control group; Group $\mathrm{A}=$ anesthetic cocktail group)

\# Diagnosis: $\mathrm{D}=$ Degenerative, $\mathrm{F}=$ Fracture, $\mathrm{FB}=$ Failed back surgery

* Statistically significant; $p$-value $<0.05$

Table 2: Comparison of the outcomes between two groups ${ }^{\#}$

\begin{tabular}{|c|c|c|c|}
\hline Data & $\begin{array}{c}\text { Group } N \\
(\mathbf{N}=27)\end{array}$ & $\begin{array}{c}\text { Group A } \\
(\mathbf{N}=\mathbf{2 7})\end{array}$ & $p$-value \\
\hline \multicolumn{4}{|l|}{ Postoperative morphine consumption (mg) } \\
\hline 2 hours & $3(0-11)$ & $2(0-11)$ & 0.320 \\
\hline 4 hours & $2(0-13)$ & $1(0-5)$ & $0.048 *$ \\
\hline 8 hours & $3(0-7)$ & $1(0-6)$ & $0.007 *$ \\
\hline 12 hours & $3(0-7)$ & $1(0-4)$ & $0.005 *$ \\
\hline 18 hours & $3(1-13)$ & $2(0-5)$ & $0.026^{*}$ \\
\hline 24 hours & $3(0-8)$ & $2(0-8)$ & 0.166 \\
\hline \multicolumn{4}{|l|}{ Postoperative VAS for pain } \\
\hline At recovery room (0 hour) & $5(0-10)$ & $2(0-10)$ & $0.048 *$ \\
\hline 2 hours & $5(0-10)$ & $0(0-10)$ & $0.001 *$ \\
\hline 4 hours & $6(0-10)$ & $0(0-7)$ & $<0.001 *$ \\
\hline 8 hours & $5(0-8)$ & $1(0-6)$ & $<0.001 *$ \\
\hline 12 hours & $5(0-8)$ & $3(0-6)$ & $<0.001 *$ \\
\hline 18 hours & $5(0-8)$ & $3(0-10)$ & $0.001 *$ \\
\hline 24 hours & $5(0-8)$ & $4(0-8)$ & $0.018^{*}$ \\
\hline Duration of first demand of analgesia (min) & $5(1-500)$ & $30(3-576)$ & $0.013 *$ \\
\hline $\begin{array}{l}\text { Number of morphine-related side effects } \\
\text { (nausea, vomiting and pruritus) }\end{array}$ & $8(29.63)$ & $1(3.70)$ & $0.024 *$ \\
\hline
\end{tabular}

\footnotetext{
\# Data presented as mean \pm SD, except for gender, ASA physical status, diagnosis, and number of surgery levels, which are presented as numbers. While estimate blood loss presented with median with min-max in parentheses and intra-operative complication presented as incidence.

(Group $\mathrm{N}=$ control group; Group $\mathrm{A}=$ anesthetic cocktail group)

\# Diagnosis: $\mathrm{D}=$ Degenerative, $\mathrm{F}=$ Fracture, $\mathrm{FB}=$ Failed back surgery

* Statistically significant; $p$-value $<0.05$
} 
intra-articular multimodal drug injections after knee surgery such as ACL reconstruction, high tibial osteotomy and total knee arthroplasty. (17-25) Regarding spinal surgery, Kadir Ozyilmaz et al. reported that wound infiltration with levobupivacaine and tramadol resulted in eliminating postoperative analgesic demand and reducing the incidence of side effects. ${ }^{(26)}$ Moreover, combining levobupivacaine and tramadol provided significantly better analgesia compared with levobupivacaine or tramadol alone.

In our study, we used anesthetic cocktails that combine $100 \mathrm{mg}$ bupivacaine $(0.5 \%, 20 \mathrm{~mL}), 3 \mathrm{mg}$ morphine sulfate $(0.3 \mathrm{~mL})$ and $30 \mathrm{mg}$ ketorolac (1 mL). The local anesthetic bupivacaine blocks C-fiber input to the dorsal horn; and may thereby, inhibit central sensitization. This could also provide potential benefits such as inhibiting both the early inflammatory response and the late effects of this process (proliferation of capillaries and fibroblasts, collagen formation and scarring). The analgesic effect of locally administered morphine could be mediated by $\mu$-opioid receptors located in the bone. However, ketorolac alleviates pain by inhibiting cyclooxygenases 1 and 2 and lowering levels of prostaglandins at the peripheral pain receptors.

We recognize limitations in our study. First, this present study covered small numbers of subjects that might have led to statistically insignificant parameters when comparing between the two groups. Second, evaluation was performed only during the first 24 hours postoperative. Therefore, pain and opioid consumption could not be assessed after the first 24 hours until patients were discharged from the hospital. In addition, the patients in this study had various pathologies and underwent different procedures which might have interfered with interpreting outcome measurement.

In conclusion, the simple technique of wound instillation using anesthetic cocktails significantly reduced the postoperative requirements of morphine and improved pain control with lower rates of nausea and vomiting over the first postoperative day after posterior spinal surgery.

\section{Acknowledgments}

We would like to thank the Maha Vajiralongkorn Foundation for supporting this study and all enrolled participants providing the data used in this study.

\section{References}

1. Jonnavithula N, Garre S, Pasupuleti S, Durga P, Kulkarni DK, Ramachandran G .Wound instillation of local anesthetic bupivacaine for postoperative analgesia following lumbar laminectomy. Middle East J Anaesthesiol 2015; 23: 193-8.

2. Bajwa SJ, Haldar R. Pain management following spinal surgeries: an appraisal of the available options. J Craniovertebr Junction Spine 2015; 6: 105-10.

3. Gerbershagen HJ, Aduckathil S, van Wijck AJ, Peelen LM, Kalkman CJ, Meissner W. Pain intensity on the first day after Anesthesiology surgery: A prospective cohort study comparing 179 surgical procedures. Anesthesiology 2013; 118: 934-44.

4. Phillips DM. JCAHO pain management standards are unveiled. Joint commission on accreditation of healthcare organizations. JAMA 2000; 284: 428-9.

5. Eldor J. Postoperative wound analgesia. A renewed modality. J NYSORA 2009; 13: 11-9.

6. Sinatra RS, Torres J, Bustos AM. Pain management after major orthopaedic surgery: current strategies and new concepts. J Am Acad Orthop Surg 2002; 10: 117-29.

7. Kvolik S, Kristek J, Sakic K, Takac I, Gulam D. A wound infiltration as a method of postoperative analgesia. Periodicum Biologorum 2009; 111: 241-6.

8. Tammachote N, Kanitnate S, Manuwong S, Yakumpor T, Panichkul P. Is pain after TKA better with periarticular injection or intrathecal morphine? Clin Orthop Relat Res 2013; 471: 1992-9.

9. Schenk MR, Putzier M, Kugler B, Tohtz S, Voigt K, Schink T. Postoperative analgesia after major spine surgery: patient-controlled epidural analgesia versus patient-controlled intravenous analgesia. Anesth Analg 2006; 103: 1311-7.

10. Kluba T, Hofmann F, Bredanger $\mathrm{S}$, Blumenstock G, Niemeyer T. Efficacy of post-operative analgesia after posterior 
lumbar instrumented fusion for degenerative disc disease: a prospective randomized comparison of epidural catheter and intravenous administration of analgesics. Orthop Rev 2010; 2: 27-30.

11. Tian P, Fu X, Li Z, Ma X. Comparison of patient-controlled epidural analgesia and patient-controlled intravenous analgesia after spinal fusion surgery: a meta-analysis of randomized controlled trials. BMC Musculoskelet Disord 2015; 16: 388.

12. Bianconi M, Ferraro L, Traina GC, Zanoli G, Antonelli T, Guberti A, etal. Pharmacokinetics and efficacy of ropivacaine continuous wound instillation after joint replacement surgery. Br J Anaesth 2003; 91: 830-5.

13. Bulut T, Yilmazlar A, Yavascaoglu B, Sarisozen B. The effect of local anaesthetic on post-operative pain with wound instillation via a catheter for paediatric orthopaedic extremity surgery. J Child Orthop 2011; 5: 179-85.

14. Yuenyongviwat V, Pornrattanamaneewong C, Chinachoti T, Chareancholvanich K. Periarticular injection with bupivacaine for postoperative pain control in total knee replacement: a prospective randomized double-blind controlled trial. Adv Orthop 2012; 2012: 107309.

15. Bianconi M, Ferraro L, Ricci R, Zanoli $\mathrm{G}$, Antonelli $\mathrm{T}$, Giulia $\mathrm{B}$, et al. The pharmacokinetics and efficacy of ropivacaine continuous wound instillation after spine fusion surgery. Anesth Analg 2004; 98: 166-72.

16. Koh IJ, Chang CB, Seo ES, Kim SJ, Seong SC, Kim TK. Pain management by periarticular multimodal drug injection after anterior cruciate ligament reconstruction: a randomized, controlled study. Arthroscopy 2012; 28:649-57.

17. Jung WH, Takeuchi R, Chun CW, Lee JS, Ha $\mathrm{JH}$, Kim JH, et al. Efficacy of periarticular multimodal drug injection after medial opening-wedge high tibial osteotomy: a randomized, controlled study. Arthroscopy 2014; 30:1261-8.

18. Koehler D, Marsh JL, Karam M, Fruehling C, Willey M. Efficacy of surgical-Site, multimodal drug injection following operative management of femoral fractures: A randomized controlled trial. J Bone Joint Surg Am 2017; 99: 512-9.
19. Andersen LJ, Poulsen T, Krogh B, Nielsen T. Postoperative analgesia in total hip arthroplasty: a randomized double-blinded, placebo-controlled study on peroperative and postoperative ropivacaine, ketorolac, and adrenaline wound infiltration. Acta Orthop 2007; 78: 187-92.

20. Liu W, Cong R, Li X, Wu Y, Wu H. Reduced opioid consumption and improved early rehabilitation with local and intraarticular cocktail analgesic injection in total hip arthroplasty: a randomized controlled clinical trial. Pain Med 2011; 12: 387-93.

21. Moucha CS, Weiser MC, Levin EJ. Current Strategies in Anesthesia and Analgesia for Total Knee Arthroplasty. J Am Acad Orthop Surg 2016; 24: 60-73.

22. Busch CA, Shore BJ, Bhandari R, Ganapathy S, MacDonald SJ, Bourne RB, et al, Efficacy of periarticular multimodal drug injection in total knee arthroplasty. A randomized trial. J Bone Joint Surg Am 2006; 88: 959-63.

23. Kelley TC, Adams MJ, Mulliken BD, Dalury DF. Efficacy of multimodal perioperative analgesia protocol with periarticular medication injection in total knee arthroplasty: a randomized, double-blinded study. J Arthroplasty 2013; 28: 1274-7.

24. Spangehl MJ, Clarke HD, Hentz JG, Misra L, Blocher JL, Seamans DP. The Chitranjan Ranawat Award: Periarticular injections and femoral \&amp; sciatic blocks provide similar pain relief after TKA: a randomized clinical trial. Clin Orthop Relat Res 2015; 473: 45-53.

25. Ozyilmaz K, Ayoglu H, Okyay RD, Yurtlu S, Koksal B, Hanci V, et al. Postoperative analgesic effects of wound infiltration with tramadol and levobupivacaine in lumbar disk surgeries. J Neurosurg Anesthesiol 2012; 24: 331-5.

26. Gordon DB, Stevenson KK, Griffie J, Muchka S, Rapp C, Ford-Roberts K. Opioid equianalgesic calculations. J Palliat Med 1999; 2: 209-18.

27. Lacy CF. Drug information handbook. $21^{\text {st }} \mathrm{ed}$. Ohio, United Stages: Lexi-Comp; 2012.

28. McEvoy GK. American hospital formulary service drug information. 2014 ed. Maryland, United Stages: American Society of HealthSystem Pharmacists; 2014. 